\title{
Comparison of two methods of collecting induced sputum in asthmatic subjects
}

\author{
N.H. Gershman*, H.H. Wong+, J.T. Liu+, M.J. Mahlmeister+, J.V. Fahy*+
}

\begin{abstract}
Comparison of two methods of collecting induced sputum in asthmatic subjects. N.H. Gershman, H.H. Wong, J.T. Liu, M.J. Mahlmeister, J.V. Fahy. @ERS Journals Ltd 1996. ABSTRACT: The method that we have previously reported for sputum induction involves collecting the entire expectorate produced over a $20 \mathrm{~min}$ inhalation of $3 \%$ saline aerosol. This method presents the potential disadvantage of a considerable and variable salivary contribution to the induced sputum sample. In this study, we examined whether separate collection of saliva and sputum represents a better method for collecting induced sputum during sputum induction.

In 11 stable asthmatics, we compared the volume, total and differential cell counts, and eosinophil cationic protein (ECP) levels in four induced sputum samples, two performed using our previous method (Method A) and two using another method (Method B) in which subjects spit saliva into one container before coughing sputum into another.

We found that the volume of sputum obtained with Method B was lower than that obtained with Method A $(6.16 \pm 0.61$ vs $20.1 \pm 2.7 \mathrm{~mL} ; \mathrm{p}=0.003)$, as was the percentage of squamous cells $(34 \pm 4 v s 47 \pm 6 ; p=0.023)$. In addition, the ECP levels in samples collected by Method $B$ were higher $\left(261 \pm 42\right.$ vs $\left.145 \pm 26 \mathrm{ng}^{\cdot} \mathrm{mL}^{-1} ; \mathrm{p}=0.01\right)$. The differential counts of nonsquamous cells were similar except for the percent-

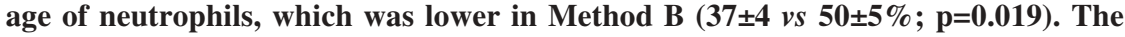
repeatability of measurements of eosinophil percentages and of ECP levels was similar for the two methods.

We conclude that separate collection of saliva and sputum yields induced sputum samples with reduced amounts of saliva and is, therefore, a better method for collecting induced sputum.

Eur Respir J., 1996, 9, 2448-2453.
\end{abstract}

\author{
* Department of Medicine, and +Cardiovas- \\ cular Research Institute, University of \\ California, San Francisco, CA, USA. \\ Correspondence: J. Fahy \\ Box 0130 University of California \\ San Francisco \\ CA 94143-0130 \\ USA
}

Keywords: Eosinophil

eosinophil cationic protein

induced sputum

reproducibility

sputum induction

Received: January 251996

Accepted after revision July 251996
Sputum induction has recently been shown to be an effective and noninvasive method for obtaining airway secretions for analysis of their cellular and biochemical constituents $[1,2]$. Analysis of induced sputum samples from asthmatic subjects has revealed higher than normal eosinophil percentages and higher than normal eosinophil cationic protein (ECP) levels $[1,2]$, data that is qualitatively similar to that obtained from analysis of bronchoalveolar lavage (BAL) [3]. In addition, analysis of induced sputum from asthmatic subjects has documented the expected changes in inflammatory markers accompanying allergen challenge $[4,5]$, isocyanate challenge [6] and prednisone therapy [7].

At the present time, there is a lack of consensus on the optimal techniques for obtaining, processing and analysing induced sputum samples. The method that we have previously reported for sputum induction involves collecting and analysing the entire expectorate, including saliva and sputum, produced over a $20 \mathrm{~min}$ inhalation of $3 \%$ saline aerosol. This method has the advantage of relative simplicity and has been shown to be valid $[2,3,5,7]$, but presents the potential disadvantage of a considerable and variable salivary contribution to the induced sputum sample. Saliva has at least two effects on induced sputum: it contributes cells and chemicals from the oropharynx and it dilutes the concentrations of subglottic cells and chemicals. The cells in saliva are more than $99 \%$ squamous cells [2], so the contribution of cells from saliva to cells in induced sputum can be controlled for by analysing the nonsquamous cells in the induced sputum sample. Chemicals, such as ECP, in saliva from asthmatic subjects tend to be much lower in concentration than the concentration in paired induced sputum samples and no different to the concentration in saliva from healthy subjects [2]. Thus, we have found that saliva in induced sputum does not preclude demonstration of differences either in cells or chemicals between healthy and asthmatic subjects, or in asthmatic subjects before and after allergen challenge [5] or steroid treatment [7]. The principal effect of saliva on fluid phase measurements in induced sputum, therefore, seems to be dilutional. The extent of this dilution is likely to be variable, however, and could impact adversely on the reproducibility of the measurements.

To reduce the contribution of saliva to the induced sputum sample, Keatings et al. [8] have collected sputum and saliva separately during sputum induction, whereas PIN et al. [1] have restricted analysis of induced sputum to plugs of mucus extracted from the sample. In this study, to determine whether the amounts of saliva 
in induced sputum can be reduced and if this reduction increases the concentrations of cells and chemicals or improves their reproducibility, we compared the total and differential cell counts and the levels of ECP in induced sputum collected on two occasions using our previously published method [2], and on two occasions using a modification of the method of KEATINGS et al. [8], whereby induced sputum and saliva are collected in separate containers during the induction procedure.

\section{Subjects and methods}

\section{Subjects}

Eleven atopic asthmatic subjects were studied (table 1). These subjects were recruited from our asthma subject database, which consists of individuals who responded to newspaper, radio and bulletin board advertisements. Inclusion criteria were a history of symptoms of asthma, bronchial hyperreactivity to methacholine (provocative concentration producing a $20 \%$ fall in forced expiratory volume in one second $\left.(\mathrm{PC} 20) \leq 8 \mathrm{mg} \cdot \mathrm{mL}^{-1}\right)$. All subjects had been on a stable therapeutic regimen for their asthma for the 4 weeks prior to study entry. Exclusion criteria were age greater than 65 yrs, a history of lung disease other than asthma, or a history of an upper respiratory infection in the preceding 4 weeks. The subjects signed consent forms approved by the Committee on Human Research at the University of California, San Francisco.

\section{Study design}

The study involved five visits to the laboratory. During the first visit, consent was obtained and spirometry, allergen skin testing and methacholine challenge testing were performed. The four subsequent visits involved a sputum induction procedure, with each visit approximately $72 \mathrm{~h}$ apart. Before the second visit, each subject was randomized to undergo sputum induction using one of two collection methods: Method A (entire expectorate collected in one container); or Method B (expectorate collected in two containers, one container for saliva and

Table 1. - Clinical characteristics of the study subjects

\begin{tabular}{lcccccc}
\hline $\begin{array}{l}\text { Subject } \\
\text { No. }\end{array}$ & $\begin{array}{c}\text { Age } \\
\text { yrs }\end{array}$ & Sex & Treatment & $\begin{array}{c}\text { FEV1 } \\
\text { L }\end{array}$ & $\begin{array}{c}\text { FEV1 } \\
\% \text { pred }\end{array}$ & $\begin{array}{c}\text { PC20 } \\
\mathrm{mg} \cdot \mathrm{mL}^{-1}\end{array}$ \\
\hline 1 & 29 & F & B & 2.7 & 90 & 0.38 \\
2 & 53 & M & B & 2.3 & 66 & 0.09 \\
3 & 35 & M & B & 2.7 & 69 & 0.28 \\
4 & 26 & F & B, ICS & 3.4 & 113 & 0.82 \\
5 & 33 & M & B & 3.7 & 84 & 0.82 \\
6 & 23 & F & B & 3.2 & 103 & 0.08 \\
7 & 27 & F & B & 3.2 & 107 & 0.74 \\
8 & 33 & M & B & 3.7 & 89 & 0.17 \\
9 & 28 & F & B & 2.7 & 84 & 0.08 \\
10 & 33 & M & B & 3.9 & 93 & 0.17 \\
11 & 25 & M & B & 4.1 & 93 & 0.47 \\
\hline Mean & 31 & & & 3.2 & 90 & $0.26^{*}$ \\
\hline
\end{tabular}

F: female; M: male; FEV1: forced expiratory volume in one second; PC20: the dose of methacholine causing a $20 \%$ fall in FEV1; B: beta-agonist; ICS: inhaled corticosteroid; \% pred: percentage of predicted value. *: geometric mean. one container for induced sputum) during the second and third visits, and the other method (A or B) during the fourth and fifth visits.

\section{Methods}

Spirometry, methacholine challenge, and allergen skin testing were performed using methods described previously [3].

Sputum induction. All subjects were pretreated with 360 $\mu \mathrm{g}$ albuterol administered by metered dose inhaler, and were then seated in a Nuaire aerosol containment chamber (model No. NU-810-224, Plymouth, MN, USA). They inhaled nebulized sterile $3 \%$ saline for $20 \mathrm{~min}$ from a DeVilbiss Ultraneb 99 ultrasonic nebulizer, the reservoir of which was filled with $150 \mathrm{~mL}$ of $3 \%$ saline (this nebulizer generates particles of a mean mass median diameter of $4.5 \mathrm{~mm}$, and has an output of $6.2 \mathrm{~mL} \cdot \mathrm{min}^{-1}$ ). During the induction procedure, lung function was carefully monitored by regular measurements of peak expiratory flow (PEF) or spirometry. In all subjects, PEF was monitored at 4 min intervals. Baseline values for PEF and forced expiratory volume in one second (FEV1) were defined as the post albuterol values on that day. Subjects whose PEF declined to less than $80 \%$ of their baseline during sputum induction were switched to monitoring by spirometry. If the FEV 1 also declined to $<80 \%$ of baseline, then sputum induction was discontinued. If the FEV1 declined to $<90 \%$ but $>80 \%$ of baseline, then spirometry was monitored at 2 min intervals and sputum induction was discontinued if the FEV1 declined to $<80 \%$ of baseline. If the FEV 1 declined to $<100 \%$ but $>90 \%$ of baseline, then spirometry was monitored at 4 min intervals. If further monitoring of spirometry revealed that the FEV1 declined to $<90 \%$ but $>80 \%$ of baseline, then the frequency of spirometry was increased to 2 min. If the FEV1 then declined to less than $80 \%$ of baseline, sputum induction was discontinued.

Sputum collection, Method A. In this method, the subjects were encouraged to cough throughout the hypertonic saline inhalation and to expectorate all secretions, including both sputum and saliva, into a clean plastic container. In addition, the inhalation was interrupted every $2 \mathrm{~min}$, at which time the subject was asked to forcefully cough up secretions.

Sputum collection, Method B. This method was identical to Method A, except that subjects were asked to spit saliva into one plastic container before coughing sputum into another. Saliva samples collected during the sputum induction procedure using this method were retained for analysis (22 samples). In addition, for each subject, one sample of saliva collected before the first sputum induction procedure using Method B was analysed (11 samples).

Sputum and saliva processing and cell counts. Sputum collected by both methods and the saliva samples were processed using methods identical to those described previously [2]. Briefly, $250 \mu \mathrm{L}$ of homogenized sputum or saliva (diluted in saline to prevent cell crowding on 
the slide) were spun in a cytocentrifuge (model 7 cytospin; Shandon Scientific, Sewickley, PA, USA), and stained using Diff-Quik ${ }^{\circledR}$ stain (Baxter Scientific Products, Miami, FL, USA). For sputum, all cells were counted, which allowed calculation both of the squamous cell percentage of the total cell sample and the epithelial, macrophage, neutrophil, eosinophil and lymphocyte percentages of the nonsquamous cells in the sample. At least 200 nonsquamous cells on each sputum slide were read by the same investigator.

Our definition of an adequate induced sputum sample was one in which there were fewer than $80 \%$ squamous cells on differential cell analysis. For saliva samples only, total cell percentages were calculated (nonsquamous cell differentials were not calculated). The homogenized sputum and saliva samples not used for total and differential cell counts were centrifuged at $1,037 \times \mathrm{g}$ for $5 \mathrm{~min}$. The supernatant was aspirated and frozen at $70^{\circ} \mathrm{C}$ for later analysis.

ECP assay. ECP concentrations in induced sputum and saliva supernatant samples were determined using a sensitive radioimmunoassay (Pharmacia Diagnostics Inc., Fairfield, NJ, USA), with a reported detection limit of $<2 \mathrm{ng} \cdot \mathrm{mL}^{-1}$, a reported between assay coefficient of variation of $0.5 \%$, and a reported within assay coefficient of variation of $10.9 \%$. For ECP analysis in induced sputum, we found a between assay variation of $5.0 \%$ and within assay variations ranging $1.7-12.9 \%$.

\section{Statistical analysis}

The data are presented as mean and SEM. A paired ttest was used to analyse the means for each of the two methods on individual subjects; a nonparametric equivalent was used for data not normally distributed (e.g. $\mathrm{ECP}$, total cell count). An unpaired t-test was used to compare squamous cell percentages of saliva samples. The reproducibility of each sputum measurement was determined in two ways: 1) by calculating the coefficient of variation for the two measurements using each method on individual subjects; and 2) using the method of BLAND and Altman [9]. The coefficients of variation for each method were compared by the Wilcoxon rank-sum test. The four determinations of preinduction FEV1 were compared using a repeated-measures analysis of variance (ANOVA). A p-value of $<0.05$ was considered significant.

\section{Results}

All subjects produced adequate induced sputum samples (defined as induced sputum with $<80 \%$ squamous cells) with Method $\mathrm{B}$, but 2 of 11 subjects did not produce adequate samples on at least one occasion while performing Method A. Every sample, however, was included for analysis. Separate collection of sputum and saliva resulted in induced sputum samples with reduced amounts of saliva, as evidenced by a $28 \%$ reduction in the percentage of squamous cells, an $80 \%$ increase in the concentration of ECP, a $140 \%$ increase in the concentration of nonsquamous cells, and a $69 \%$ reduction in the volume of secretions compared to those induced sputum samples where the entire expectorate was included for analysis.

\section{Volume, cell counts, cell differentials and ECP levels} in induced sputum

The volume of induced sputum collected by Method B was $69 \%$ lower than the volume collected using Method A (table 2). In addition, the median total cell count of induced sputum collected using Method B was 110\% higher than that using Method A, and the median total nonsquamous cell count was $140 \%$ higher using Method B (table 2). Furthermore, the squamous cell percentage in induced sputum was $28 \%$ lower with Method B than Method A, and the neutrophil percentage was $25 \%$ lower (fig. 1 and table 2). The differential cell counts for all

Table 2. - Volume of secretions, total cell counts, cell differentials and ECP concentration in saliva and induced sputum samples

\begin{tabular}{|c|c|c|c|c|}
\hline & $\begin{array}{c}\text { Saliva } \\
\text { prior to } \\
\text { sputum induction }\end{array}$ & $\begin{array}{c}\text { Saliva } \\
\text { during sputum } \\
\text { induction (Method B) }\end{array}$ & $\begin{array}{l}\text { Induced } \\
\text { sputum } \\
\text { (Method A) }\end{array}$ & $\begin{array}{l}\text { Induced } \\
\text { sputum } \\
\text { (Method B) }\end{array}$ \\
\hline Volume $\mathrm{mL}$ & $3.5 \pm 0.8$ & $16.8 \pm 1.8$ & $20.1 \pm 2.7$ & $6.16 \pm 0.61 *$ \\
\hline Total cell count ${ }^{\ddagger} \times 10^{5} \cdot \mathrm{mL}^{-1}$ & $\begin{array}{c}12.6 \\
(4.4-60.4)\end{array}$ & $\begin{array}{c}4.0 \\
(1.2-14.4)\end{array}$ & $\begin{array}{c}11.5 \\
(1.2-41.0)\end{array}$ & $\begin{array}{c}24.2 \\
(2.8-67.4)^{*}\end{array}$ \\
\hline Squamous cells \% & $99 \pm 0.5$ & $86 \pm 2^{\S}$ & $47 \pm 6$ & $34 \pm 4 *$ \\
\hline \multicolumn{5}{|l|}{ Total nonsquamous } \\
\hline cell count ${ }^{\ddagger} \times 10^{5} \cdot \mathrm{mL}^{-1}$ & $\begin{array}{c}0.0 \\
(0.0-1.38)\end{array}$ & $\begin{array}{c}0.42 \\
(0.02-2.6)^{\S}\end{array}$ & $\begin{array}{c}6.9 \\
(0.20-35.0)\end{array}$ & $\begin{array}{c}16.5 \\
(1.0-43.1)^{*}\end{array}$ \\
\hline Eosinophils $\%^{\dagger}$ & $0.15 \pm 0.11$ & $0.19 \pm 0.11$ & $5.7 \pm 1.4$ & $6.3 \pm 1.3$ \\
\hline Macrophages $\%^{\dagger}$ & $0.15 \pm 0.11$ & $2.00 \pm 0.74 \S$ & $40.6 \pm 4.5$ & $49.1 \pm 4.1 *$ \\
\hline Neutrophils $\%^{\dagger}$ & $0.27 \pm 0.16$ & $10.8 \pm 2.11^{\S}$ & $48.9 \pm 5.0$ & $36.8 \pm 4.0 *$ \\
\hline Lymphocytes $\%^{\dagger}$ & $0.00 \pm 0.00$ & $0.08 \pm 0.04$ & $1.1 \pm 0.2$ & $1.7 \pm 0.2$ \\
\hline Epithelial cells $\%^{\dagger}$ & $0.11 \pm 0.08$ & $0.42 \pm 0.19$ & $3.7 \pm 1.1$ & $6.0 \pm 1.1^{*}$ \\
\hline $\mathrm{ECP} \mathrm{ng} \cdot \mathrm{mL}^{-1}$ & $32 \pm 11$ & $28 \pm 6$ & $145 \pm 26$ & $261 \pm 42 *$ \\
\hline
\end{tabular}

¥: total cell counts expressed as the median and range; all other values are presented as mean \pm SEM. $\dagger$ : saliva differential counts are calculated from cells in the sample, i.e. squamous and nonsquamous cells; induced sputum cell differential counts are calculated as the percentage of the nonsquamous cells. ECP: eosinophil cationic protein. \&: $\mathrm{p}<0.05$, significantly different from saliva collected preinduction. *: $\mathrm{p}<0.05$, significantly different from induced sputum collected using Method A. 

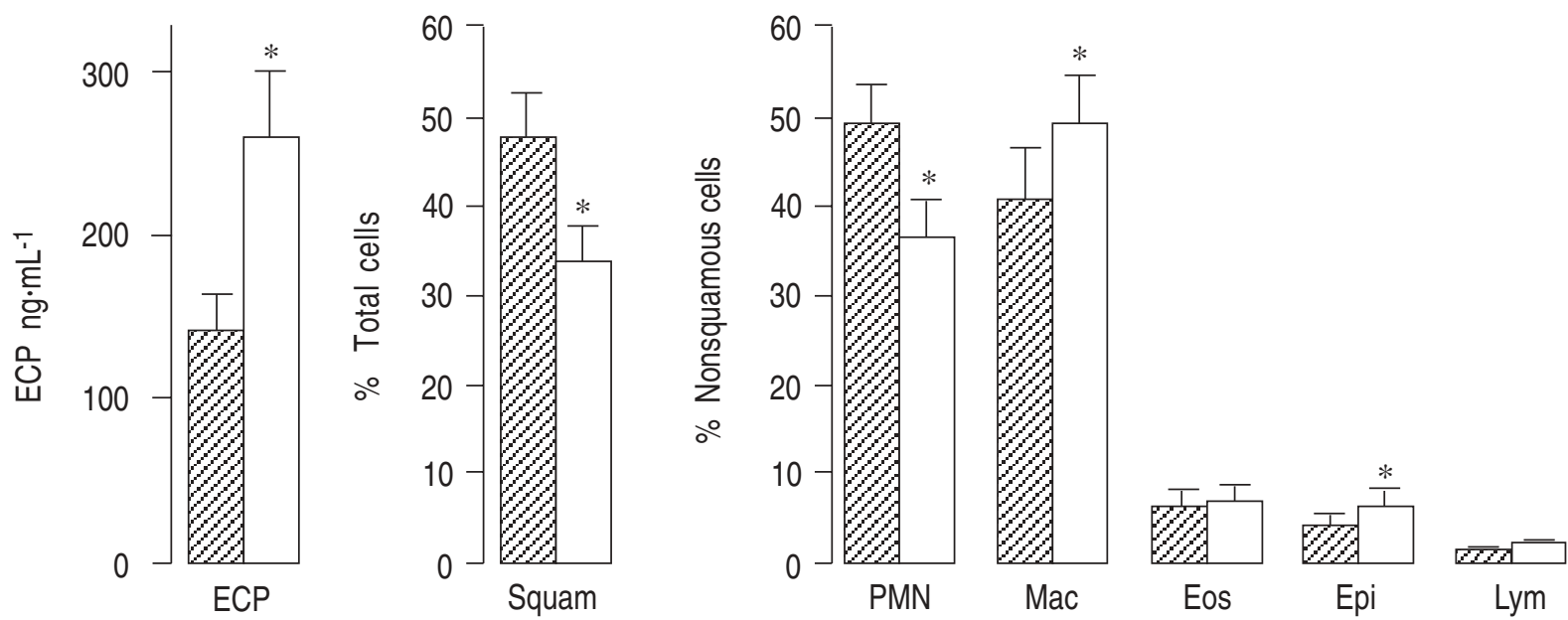

Fig. 1. - Average eosinophil cationic protein (ECP) levels and average percentages of squamous and nonsquamous cells on two occasions in induced sputum collected as the entire expectorate (Method A), or by separating sputum and saliva (Method B). $\square$ : Method A; $\square$ : Method B. Squam: squamous cells; PMN: polymorphonuclear neutrophils; Mac: macrophages; EOS: eosinophils; Epi: epithelial cells; Lym: lymphocytes. * : p<0.05, significantly different from Method A.

other cell types were similar for both methods (table 2 ). The levels of ECP in induced sputum collected by Method B were on average $80 \%$ higher than those collected by Method A (fig. 1 and table 2).

Volume, cell counts, cell differentials, and ECP levels in saliva

The mean volume of saliva collected separately during sputum inductions using Method $\mathrm{B}$ was $16.8 \mathrm{~mL}$, a volume similar to the $13.9 \mathrm{~mL}$ difference in volume of induced sputum samples collected using methods $\mathrm{A}$ and B (table 2). The total cell count of saliva collected before sputum induction was significantly higher than the total cell count of saliva collected during sputum induction (table 2), and the percentage of squamous cells in saliva collected before sputum induction was significantly higher than the percentage of squamous cells in saliva collected during sputum induction (table 2). The other cell types in the saliva samples collected during sputum induction were principally neutrophils and macrophages (table 2). In addition, the levels of ECP in saliva collected before or during sputum induction were not significantly
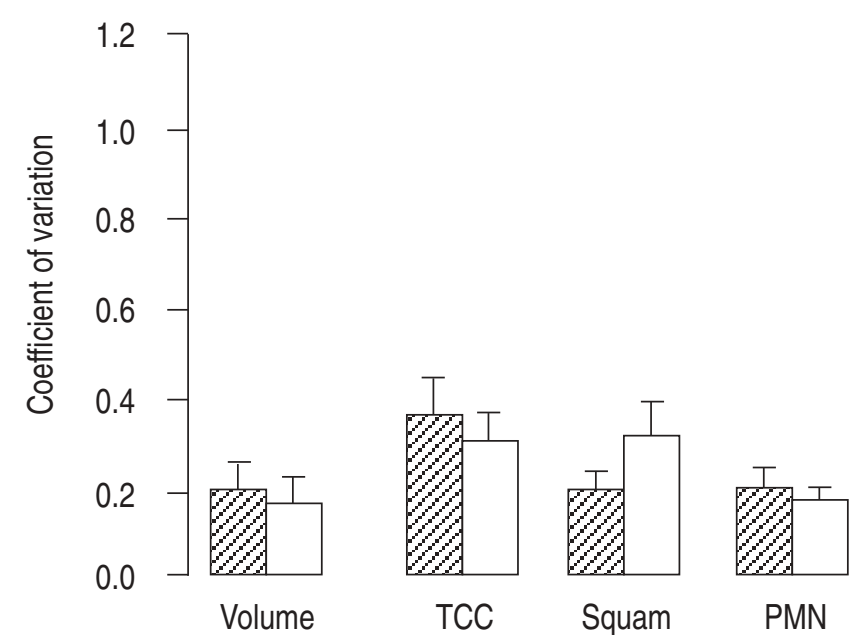

PMN different and were nine fold lower than the levels in the induced sputum samples (table 2).

\section{Reproducibility}

The coefficients of variation for the measurements of induced sputum volume, total cell counts, squamous cell, eosinophil, macrophage and neutrophil percentages and ECP levels were not significantly different for Methods $A$ and B (fig. 2). The coefficients of variation for the two measurements of epithelial cell and lymphocyte percentages in induced sputum were significantly lower for Method B (fig. 2). In addition, Bland-Altman plots of eosinophil percentages and ECP levels measured in induced sputum collected on two occasions using Methods $\mathrm{A}$ and $\mathrm{B}$ demonstrate similar reproducibility for both these outcomes with both methods (fig. 3).

\section{Safety}

Within individual subjects there was no significant difference between the baseline FEV1 values performed

Fig. 2. - Coefficient of variation for measurements of volume, nonsquamous cell count, nonsquamous cell differentials and eosinophil cationic protein (ECP) in induced sputum collected using Method A ( $\square$ ) and Method B ( $\square$ ). TCC: total cell count. For further definitions see legend to figure 1 . *: $\mathrm{p}=0.02$, significantly smaller than Method A. 


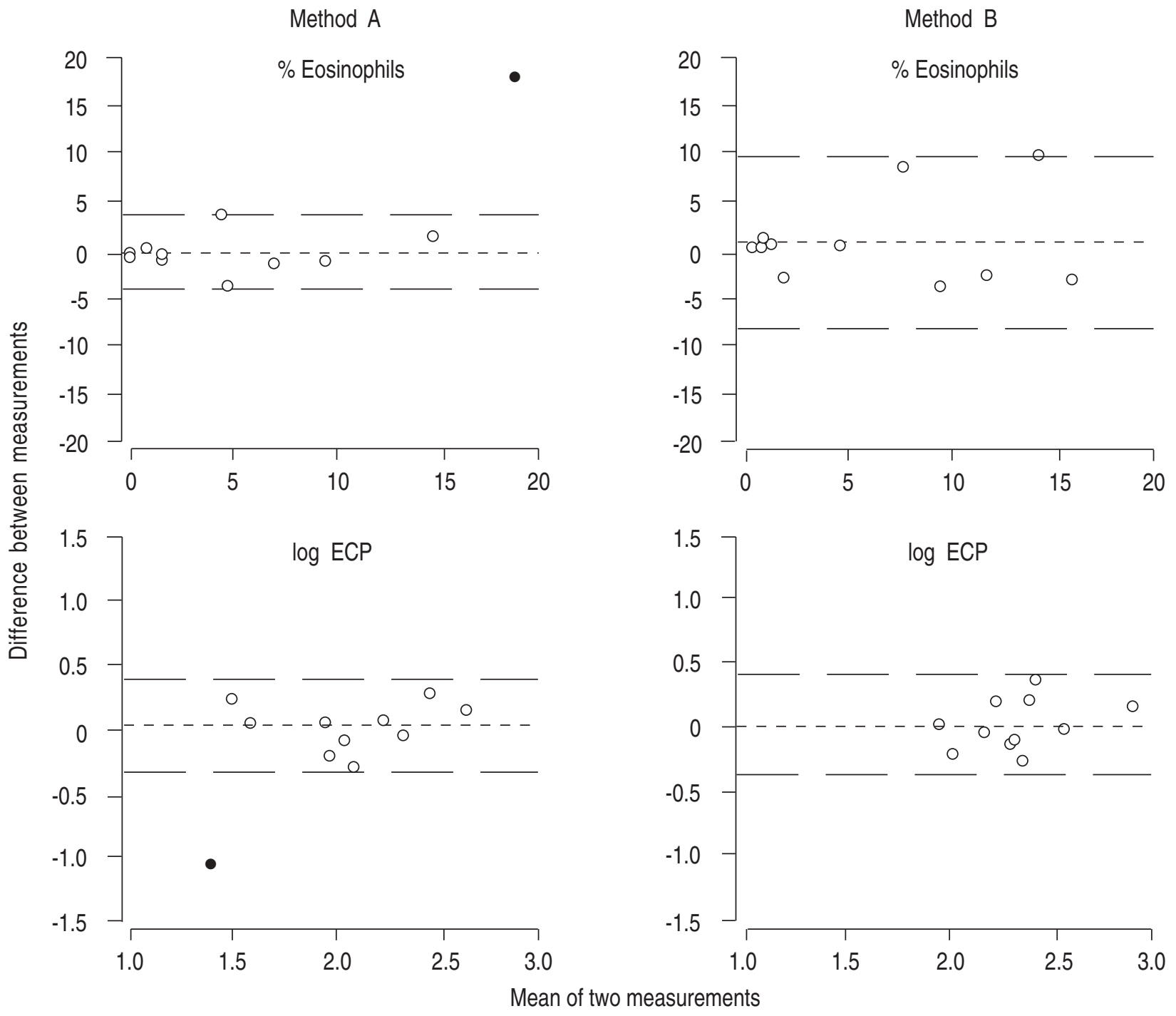

Fig. 3. - Bland Altman plots (difference between two measurements versus mean of same two measurements) for repeated measurements of eosinophil percentage (upper panels) and log transformed eosinophil cationic protein (ECP) levels (lower panels) in induced sputum collected using Method A (left panels) and Method B (right Panels). For calculation of the mean and standard deviation of the differences of repeated measurements of eosinophil percentages and ECP levels in induced sputum collected using Method A, the outliers (•) were excluded. Dashed lines represent mean $\pm 2 \mathrm{SD}$ [9].

prior to each sputum induction. The average fall from baseline (post-albuterol) in FEV1 immediately after sputum induction was $0.74 \pm 0.74 \%$. The largest fall in FEV1 from baseline was $15 \%$, and in 28 of the 44 sputum inductions there was no detectable change in FEV1.

\section{Discussion}

In this study, we found that separate collection of sputum and saliva resulted in induced sputum samples with reduced amounts of saliva, as evidenced by a $28 \%$ reduction in the percentage of squamous cells, an $80 \%$ increase in the concentration of ECP, a $140 \%$ increase in the number of nonsquamous cells, and a $69 \%$ reduction in the volume of secretions relative to those induced sputum samples where the entire expectorate was included for analysis. The reduced amounts of saliva in the induced sputum translated into more acceptable samples by the criterion of a squamous cell percentage less than $80 \%$ but, surprisingly, did not translate into better reproducibility of the measurements of cells or chemicals in the fluid phase. Overall, we believe that the data demonstrate that separate collection of sputum and saliva represents a better method of collecting airway secretions during sputum induction than collection of the entire expectorate.

Separate collection of sputum and saliva during sputum induction (Method B) yielded induced sputum samples with a lower volume and with a lower percentage of squamous cells than induced sputum collected as the entire expectorate during sputum induction (Method A). These findings indicate that asthmatic subjects can enrich their induced sputum with subglottic secretions, if they select and separate saliva from subglottic secretions during sputum induction. Notably, the analysis of cells and chemicals in the material separated as saliva by the subjects during sputum induction revealed a cell and chemical profile very similar to that of the control saliva sample collected before sputum induction began. This 
is reassuring, because it indicates that subglottic material is not being mistakenly discarded as saliva. The principal difference between saliva collected before and during sputum induction was that the latter had a higher neutrophil percentage $(10 v s<1 \%)$. This finding suggests that hypertonic saline may elicit a neutrophilic response from the oral mucosa during sputum induction. This, in turn, may explain the finding that induced sputum col-lected by Method A had a significantly higher neutrophil percentage than induced sputum collected by Method B.

The percentages of eosinophils among the nonsquamous cells in the induced sputum samples collected either by Method A or Method B were remarkably similar (fig. 1 and table 2). The reproducibility of the eosinophil percentages measured three days apart using both methods was also remarkably similar (figs. 2 and 3). Together these findings indicate that calculating the eosinophil percentage of the nonsquamous cells in induced sputum is a good method for controlling for the presence of saliva.

The average concentration of ECP in induced sputum collected by Method B was $261 \mathrm{ng} \cdot \mathrm{mL}^{-1}$, nearly twice the average concentration of ECP in induced sputum collected by Method A, and nearly nine times the average concentration in saliva. The more concentrated supernatants obtained from induced sputum collected by Method B probably reflect a reduction in the amount of saliva and, thus, a reduction in the dilution factor attributable to saliva in these induced sputum samples. We expected this reduction in the dilutional effects of saliva to improve the reproducibility of ECP measurements in the fluid phase but, surprisingly, the reproducibility of ECP measurements in the induced sputum from both methods were similar (figs. 2 and 3). Two factors may explain this surprising result. Firstly, the average coefficient of variation for ECP measurements in induced sputum collected as an entire expectorate (Method A) is quite low at 0.32 , and therefore not easy to improve. Secondly, reducing the amount of saliva in induced sputum by a separate collection method (Method B) may not necessarily reduce the variability of the dilutional effect of saliva from one induction to the next.
In summary, we found that separate collection of sputum and saliva resulted in induced sputum samples that are more concentrated in secretions from the subglottic airways. We conclude that separate collection of sputum and saliva during sputum induction is a better method of collecting induced sputum during sputum induction than collection of the entire expectorate.

\section{References}

1. Pin I, Gibson PG, Kolendowicz R, et al. Use of induced sputum cell counts to investigate airway inflammation in asthma. Thorax 1992; 47: 25-29.

2. Fahy JV, Liu J, Wong H, Boushey HA. Cellular and biochemical analysis of induced sputum from asthmatic and from healthy subjects. Am Rev Respir Dis 1993; 147: 1126-1131.

3. Fahy JV, Wong HH, Liu J, Boushey HA. Comparison of samples collected by sputum induction and bronchoscopy from asthmatic and healthy subjects. Am J Respir Crit Care Med 1995; 152: 53-58.

4. Pin I, Freitag AP, O'Byrne PM, et al. Changes in the cellular profile of induced sputum after allergen-induced asthmatic responses. Am Rev Respir Dis 1992; 145: 1265-1269.

5. Fahy JV, Liu J, Wong H, Boushey HA. Analysis of cellular and biochemical constituents of induced sputum after allergen challenge: a method for studying allergic airway inflammation. J Allergy Clin Immunol 1994; 93: 1031-1039.

6. Maestrelli P, Calcagni PG, Saetta M, et al. Sputum eosinophilia after asthmatic responses induced by isocyanates in sensitized subjects. Clin Exp Allergy 1994; 24: 29-34.

7. Claman D, Boushey HA, Liu J, Wong H, Fahy JV. Analysis of induced sputum to examine the effects of prednisone on airway inflammation. J Allergy Clin Immunol 1994; 94: 861-869.

8. Keatings VM, Collins PD, Scott DM, Barnes PJ. Differences in interleukin-8 and tumour necrosis factor-alpha in induced sputum from patients with chronic obstructive pulmonary disease and asthma. Am J Respir Crit Care Med 1996; 153: 530-534.

9. Bland JM, Altman DG. Statistical methods for assessing agreement between two methods of clinical measurement. Lancet 1986; i: 307-310. 